\title{
DUKUNGAN SUAMI PADA AKSEPTOR KB IUD DI DESA CARUBAN KECAMATAN RINGINARUM KABUPATEN KENDAL
}

\author{
HUSBAND SUPPORT WITH THE USE OF IUD IN WOMEN IN THE VILLAGE CARUBAN \\ RINGINARUM DISTRICT KENDAL
}

\author{
Sri Rahayu ${ }^{1)}$, Rini Edi Hastuti' \\ ${ }^{1) 2)}$ Akbid UNISKA Kendal \\ Email : virakina@gmail.com
}

\begin{abstract}
ABSTRAK
Tingginya angka kematian ibu di Indonesia yang mencapai 307 per 100.000 kelahiran hidup (SDKI, 2002), maka Departemen Kesehatan RI menetapkan kebijakan dalam penurunan AKI. Dalam upaya mempercepat penurunan AKI pada dasarnya mengacu pada intervensi strategis "Empat Pilar Safe Motherhood" yang salah satu isinya yaitu program Keluarga Berencana (KB). Maka dari itu pemerintah menyediakan berbagai macam kontrasepsi yang salah satunya adalah Alat Kontrasepsi Dalam Rahim (AKDR). Akan tetapi kontrasepsi paling banyak digunakan para peserta KB aktif adalah suntik 2.659 (56,71\%), pil 1.042 (22,22\%) dan kondom 19 (4,05\%). Desa Caruban memiliki PUS sebanyak 768, peserta KB aktif adalah 612 (77,8\%) dan yang drop out 23 (3,75\%). Tujuan penelitian mengetahui dukungan suami dengan penggunaan kontrasepsi IUD pada akseptor wanita di Desa Caruban Kecamatan Ringinarum Kabupaten Kendal. Jenis penelitian adalah deskriptif korelasi dengan pendekatan cross sectional. Variabel bebas adalah dukungan suami dan variabel terikat adalah penggunaan kontrasepsi IUD. Sampel penelitian 86 akseptor pengguna kontrasepsi IUD. Pengumpulan data menggunakan angket. Analisis data secara univariat dan bivariat dengan uji statistik chi square. Hasil penelitian menggambarkan suami mendukung penggunaan Kontrasepsi IUD 48 (55,8\%), sedangkan suami yang tidak mendukung hanya 38 (44,2\%). Analisis bivariat didapatkan $48(55,8 \%)$ yang mendapat dukungan suami menggunakan kontrasepsi IUD, sedangkan yang mendapat dukungan suami tetapi tidak menggunakan kontrasepsi IUD sebanyak 39 responden (45,3\%). Hasil uji statistik nilai p value 0,004 berarti ada hubungan antara dukungan suami dengan penggunaan kontrasepsi IUD pada akseptor wanita. Disarankan para akseptor KB menggunakan kontrasepsi IUD dan suami diharapkan mendukung dan mendampingi ibu agar mengikuti keluarga berencana.
\end{abstract}

Kata Kunci : Dukungan suami, pengguna, KB IUD

\begin{abstract}
The maternal mortality rate in Indonesia reaches 307 per 100.000 live births (SDKI,2002), the Ministry of Health established a policy to reducing maternal mortality. In an effort to accelerate the decline of maternal mortality rate basically refers to the strategic intervention "empat pilar safe motherhood" one of the rules that the Family Planning (KB), Thus the government to provide a wide range of contraceptives, one of which is an intrauterine device (IUD). Contraception most widely used active family planning participants are injecting 2,659 (56.71 \%). The village Caruban have as many as 768 PUS, Active is 612 (77,8\%) and the drop out $23(3.75 \%)$. This study aimed to suport her husband with the use of IUD acceptors Caruban women in the village district of Ringinarum Kendal.This type of research is dekriptive correlation with cross sectional approach The research sample acceptor 86 IUD users. Colection data using questionnaires. Data analysis of univariate and bivariate with chi squere test. The results of the study support the use of a husband destrcribes the IUD 48 (55.8\%), while the husband who does not support only 38 (44.2\%). Bivariate analysis of 48 (55.8\%) who received support husband using IUD, while the support husband but do not use the IUD much as 39 repondents (45.3\%). Statistical test result $p$ value of 0.004 means that there is a relationship between husband support the use of IUD acceptors wanita.Suggested the use of IUD acceptors and husband are expected to support and accompany the mother to follow family planning.
\end{abstract}

Keywords: husband support, IUD 


\section{PENDAHULUAN}

Program BKKBN memberikan penekanan pada kontrasepsi IUD terutama adalah $\mathrm{Cu}$ T380 A yang menjadi primadona BKKBN. Kontrasepsi yang digunakan para peserta KB aktif adalah sebagai berikut : MKJP sebanyak $931(19,85 \%)$ yaitu : IUD sebanyak $111 \quad(2,36 \%)$, MOP/MOW sebanyak 412 (8,78\%) dan implant sebanyak 408 (8,7\%). Non MKJP sebanyak 3764 (80,29\%) yaitu : suntik sebanyak 2.659 (56,71\%), pil sebanyak 1.042 (22,22\%) dan kondom sebanyak 19 (4,05\%). Di Desa Caruban memiliki jumlah PUS sebanyak 768, sementara peserta KB aktif adalah 612 $(77,8 \%)$ dan yang mengalami drop out sejumlah $23(3,75 \%)$ dengan rincian sebagai berikut: MKJP sebanyak 102 $(16,67 \%)$ yaitu: IUD sebanyak 5 $(0,81 \%)$. Faktor yang mempengaruhi pemilihan kontrasepsi IUD yang terdiri dari faktor predisposisi (usia, pendidikan, jumlah anak, pengetahuan dan sikap), faktor pemungkin (kelengkapan alat kontrasepsi, ketersediaan bidan / tenaga $\mathrm{KB}$, media informasi, dan biaya pemasangan) dan faktor penguat (dukungan suami, keluarga, tokoh agama, tokoh masyarakat, sikap petugas, dan teman). faktor dukungan suami sangat mempengaruhi ibu dalam pemilihan alat kontrasepsi yang cocok. Dukungan suami biasanya berupa perhatian dan memberikan rasa nyaman serta percaya diri dalam mengambil keputusan tersebut dalam pemilihan alat kontrasepsi (Notoatmodjo S, 2007; h.16-18)

Penelitian ini juga sejalan dengan penelitian dari Tara, F A (2014) dengan judul "Hubungan Dukungan Suami Terhadap Pemilihan Kontrasepsi IUD Di Puskesmas Curug Tangerang" dan diperoleh kesimpulan bahwa ada hubungan yang signifikan antara dukungan suami terhadap pemilihan kontrasepsi IUD dengan $p$ value $<0,05$.

Tujuan penelitian untuk mengetahui hubungan dukungan suami dengan penggunaan KB IUD pada akseptor wanita di desa Caruban Kecamatan Ringinarum Kabupaten Kendal.

\section{METODE PENELITIAN}

Jenis penelitian adalah deskriptif korelasi. penelitian deskriptif kuantitatif dengan pendekatan cross sectional. Variabel bebas adalah dukungan suami dan sebagai variabel terikat adalah penggunaan kontrasepsi IUD. Sebanyak 86 akseptor pengguna kontrasepsi IUD menjadi sampel penelitian. Pengumpulan data dilakukan menggunakan angket Analisis data dilakukan secara univariat ( distribusi frekuensi) dan analisis bivariat (tabel silang dan uji statistik chi square). Alat pengumpul menggunakan kuesioner , untuk itu perlu diuji di lapangan. Populasi yang digunakan dalam penelitian ini adalah seluruh akseptor wanita yang berada di Desa Caruban Kecamatan Ringinarum Kabupaten Kendal pada bulan April 2015 sebanyak 621 akseptor wanita, sampel yang digunakan sebanyak 86 responden. Dalam pengambilan sampel adalah Simple Random Sampling atau pengambilan sampel dengan cara acak tanpa memperhatikan strata yang ada dalam anggota populasi. Dengan mengambil lotere secara acak sejumlah 86 reponden sebagai sampel, Analisa yang dilakukan terhadap tiap variabel dari hasil penelitian dalam analisis ini hanya menghasilkan distribusi dan persentase dari tiap variabel yang diteliti. Setalah itu menggunakan analisa bivariat dengan menggunakan 
$\mathrm{X}^{2} \quad$ (chisquare). (Sugiyono, 2012; h.231).

\section{HASIL DAN PEMBAHASAN}

Dalam melakukan penelitian di Desa Caruban dengan menggunakan kuesioner, sebanyak 86 responden diperoleh hasil penelitian sebagai berikut:

1. Analisa Univariat

a. Dukungan Suami

Tabel .1 Distribusi Frekuensi

Dukungan Suami penggunaan IUD

\begin{tabular}{lcc}
\hline Dukungan Suami & Frekuensi & Persentase \\
\hline Mendukung & 48 & $55.8 \%$ \\
Tidak Mendukung & 38 & $44.2 \%$ \\
\hline Total & 86 & $100.0 \%$ \\
\hline
\end{tabular}

Berdasarkan tabel .1 diatas dapat dilihat bahwa sebagian besar suami mendukung dalam penggunaan KB IUD yaitu sebanyak 48 responden $(55,8 \%)$, sedangkan suami yang tidak mendukung hanya 38 responden (44,2\%). Dikarenakan jawaban responden dalam penelitian ini sebanyak 97,67\% mengatakan suami bersikap acuh tak acuh sehingga akseptor dalam menggunakan KB IUD kurang. Maka diharapkan bidan dapat meningkatkan pelayanan kebidanan dalam memberikan pendidikan kesehatan kepada akseptor KB tentang manfaat atau kelebihan dari KB IUD dan memotivasi suami untuk selalu memberikan dukungan kepada istri agar menggunakan kontrasepsi jangka panjang khususnya KB IUD.

b. Penggunaan KB IUD

Tabel .2 Distribusi Frekuensi Penggunaan KB IUD

\begin{tabular}{lcc}
\hline Penggunaan KB IUD & Frekuensi & Persentase \\
\hline Menggunakan KB IUD & 9 & $10,5 \%$ \\
Tidak Menggunakan & 77 & $89,5 \%$
\end{tabular}

KB IUD

\begin{tabular}{lll}
\hline Total & 86 & $100,0 \%$ \\
\hline
\end{tabular}

Berdasarkan Tabel.2 menunjukan bahwa mayoritas responden sebanyak 77 orang responden $(89,5 \%)$ tidak menggunakan KB IUD sedangkan sebanyak 9 responden $(10,5 \%)$ yang menggunakan KB IUD. Dari hasil penelitian ini diperoleh hasil bahwa mayoritas respoden tidak menggunakan KB IUD (89,5\%). Sebagian akseptor KB di Desa Caruban Kecamatan Ringinarum tidak menggunakan KB IUD dikarenakan beberapa faktor, diantaranya mereka merasa malu dan takut ketika akan dilakukan pemasangan alat kontrasepsi IUD dan akan menggangu aktivitas mereka. Sebagian besar dari mereka juga merasa khawatir dengan efek samping yang akan ditimbulkan dari penggunaan KB IUD, walaupun tenaga kesehatan sudah memberikan informasi secara mendetail terutama banyaknya keuntungan yang didapat bila menggunakan KB IUD.

Hasil penelitian ini didukung oleh penelitian dari Arief Widodo yang berjudul "Pengaruh Dukungan Suami Terhadap Kepatuhan Akseptor Melakukan KB Suntik" dengan hasil bahwa dukungan suami berpengaruh terhadap kepatuhan akseptor melakukan $\mathrm{KB}$ suntik dengan $p$ value : 0,011 dan penelitian dari Syamsiah yang berjudul "Peranan Dukungan Suami Dalam Pemilihan Alat Kontrasepsi Pada Peserta KB Di Kelurahan Serasan Jaya, Soak Baru Dan Balai Agung Kecamatan Sekayu Kabupaten Musi Banyuasin" dengan hasil adanya hubungan antara umur, pendidikan suami, jumlah anak hidup dan dukungn suami dalam pemilihan alat kontrasepsi. 
Analisa bivariat dalam penelitian ini diuraikan sebagai berikut:

Tabel. 3Distribusi Hubungan Dukungan Suami dengan Penggunaan KB IUD

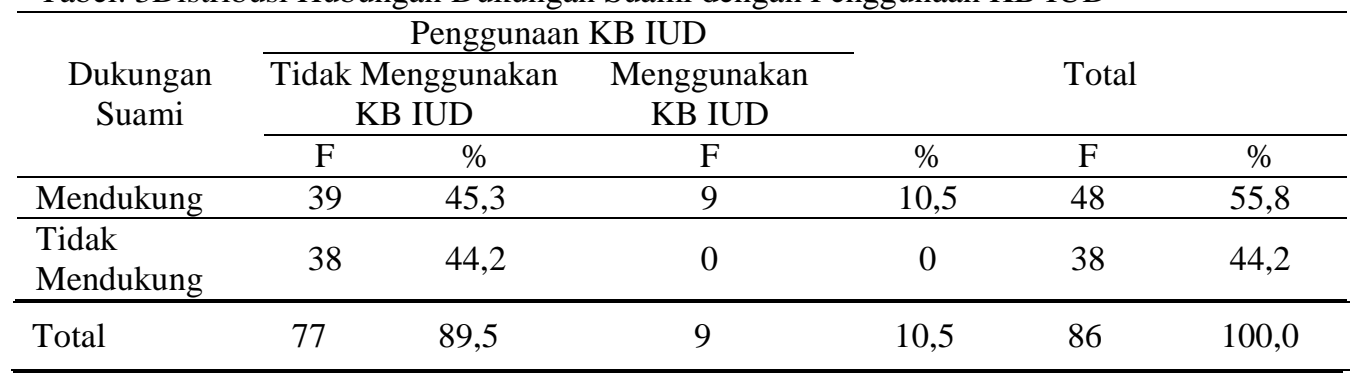

Chi Square : 0,14

Dari tabel .3 menunjukkan bahwa dari 48 responden $(55,8 \%)$ yang mendapat dukungan suami sebanyak 9 responden (10,5\%) menggunakan KB IUD, sedangkan yang mendapat dukungan suami tetapi tidak menggunakan KB IUD sebanyak 39 responden $(45,3 \%)$.

Dari 48 responden $(44,2 \%)$ yang tidak mendapatkan dukungan dari suami tidak ada satupun yang menggunakan KB IUD, sehingga ada 38 responden $(44,2 \%)$ yang tidak mendapatkan dukungan suami dan tidak menggunakan KB IUD.

Hasil uji statistik didapatkan nilai $p$ value 0,004 sehingga kurang dari taraf signifikan $5 \%(0,004 \leq 0,05)$, berarti ada hubungan yang signifikan antara dukungan suami dengan penggunaan KB IUD pada akseptor wanita

Penelitian ini juga sejalan dengan penelitian dari Tara, F A (2014) dengan judul "Hubungan Dukungan Suami Terhadap Pemilihan Kontrasepsi IUD Di Puskesmas Curug Tangerang" dan diperoleh kesimpulan bahwa ada hubungan yang signifikan antara dukungan suami terhadap pemilihan kontrasepsi IUD dengan $p$ value $<0,05$.

\section{SIMPULAN}

1. Sebagian besar suami mendukung dalam penggunaan KB IUD yaitu sebanyak 48 responden $(55,8 \%)$ p value : 0,004

2. Penggunaan KB IUD di desa Caruban sebanyak 9 responden $(10,5 \%)$

3. Hasil uji statistik didapatkan nilai $p$ value 0,004 sehingga kurang dari taraf signifikan $5 \%(0,004 \leq 0,05)$, berarti ada hubungan yang signifikan antara dukungan suami dengan penggunaan KB IUD pada akseptor wanita

\section{DAFTAR PUSTAKA}

Adhyani, AR. 2011. Faktor-Faktor yang Berhubungan Dengan Pemilihan Kontrasepsi IUD Pada Akseptor KB Wanita Usia 20-39 Tahun di wilayah Puskesmas Tlogosari Kulon Semarang Timur Tahun 2011 [Karya Tulis Ilmiah]. Semarang: FK Undip

Alimul, A. 2007. Buku Riset Keperawatan \& Teknik Penulisan Ilmiah. Jakarta; Salemba Medika. h. 32-33, 35-36, 38-39

Arief Widodo. 2012. Pengaruh Dukungan Suami Terhadap Kepatuhan Akseptor Melakukan KB Suntik [Skipsi]. Surabaya: FKM UNAIR

BKKBN. 2011. Evaluasi Pembangunan Kependudukan Dan KB BKKBN Provinsi. Jakarta; Pustaka Sinar Harapan. h. 11 2007. Keluarga Berencana Dan Kontrasepsi. Cetakan Ke-5. Jakarta; Pustaka Sinar Harapan. h. 29

Dewantari, L. 2012. Hubungan Dukungan Suami Dengan Pemilihan Alat Kontrasepsi Dalam Rahim (AKDR) Di Desa Sijambe Kecamatan Wonokerto Kabupaten Pekalongan Tahun 2012 [Karya Tulis Ilmiah]. Pekalongan: 
STIKES Muhammadiyah Pekajangan Pekalongan

Dinas Kesehatan Kabupaten Kendal. 2014. Profil kesehatan Kabupaten Kendal 2013. Kendal; Dinas Kesehatan Kabupaten Kendal. h. 54

Dinas Kesehatan Provinsi Jawa Tengah. 2013. Profil kesehatan Provinsi Jawa Tengah Tahun 2012. Semarang; Dinas Kesehatan Provinsi Jawa Tengah. h. 6163

Notoadmodjo, S. 2007. Promosi Kesehatan Dan Ilmu Perilaku. Jakarta ; Rineka Cipta. h. 12, 16, 17-18, 139-145, 218 2012. Metodologi

Penelitian Kesehatan. Jakarta; Rineka Cipta. h. 1-10, 101, 100, 105, 164-168, 176-178, 182-183
Saifuddin, A. B. 2006. Buku Acuan Nasional Pelayanan Kesehatan Maternal Dan Neonatal. Jakarta; Yayasan Bina Pustaka Sarwono Prawirohardjo. h. 23.

2006. Buku Panduan Praktis Pelayanan Kontrasepsi. Jakarta; Yayasan Bina Pustaka Sarwono Prawirohardjo. h. 74-78, 80

Siti Widiyati . 2009. Faktor-Faktor Yang Berhubungan Dengan Pemakaian AKDR (Alat Kontrasepsi Dalam Rahim) Diwilayah Kerja Puskesmas Batuah Kutai Kartanegara [Skripsi]. Makassar: Universitas Hasanuddin

Sugiyono. 2012. Statistika Untuk Penelitian. Bandung; Alfabeta. h. 231 